\title{
Performance of the GLAS Satellite Lidar Cloud and Aerosol Measurements
}

\author{
James D. Spinhirne \\ NASA Goddard Space Flight Center \\ Laboratory for Atmospheres/613.1 \\ Greenbelt, MD 20771 \\ 3016146274 \\ james.d.spinhirne@nasa.gov
}

Abstract-Launched in early 2003, the Geoscience Laser Altimeter System (GLAS) on the Ice, Cloud and Land Elevation Satellite is the first polar orbiting satellite lidar and is intended for comprehensive earth science applications covering surface altimetry for ice sheets and vegetation and atmospheric profiling. The instrument design includes high performance observations of the distribution and optical scattering cross sections of atmospheric clouds and aerosol. The backscatter lidar operates at two wavelengths, 532 and $1064 \mathrm{~nm}$. For the atmospheric cloud and aerosol measurements, the $532 \mathrm{~nm}$ channel was designed for ultra high efficiency with solidstate photon counting detectors and etalon filtering. Data processing algorithms were developed to calibrate and normalize the signals and produce global scale data products of the height distribution of cloud and aerosol layers and their optical depths and particulate scattering cross sections up to the limit of optical attenuation. Since the initial production of data products there has been extensive studies of the accuracy and limitation of the data products. Studies include the statistical analysis of results, quality checking surveys and inter-comparison to ground and airborne measurements. The paper concentrates on the effectiveness, results and limitations of the atmospheric lidar channel design and data product algorithms. Overall, given known instrument problems uncorrected before launch, the results validate the expectations of the lidar design. ${ }^{12}$

\section{TABLE OF CONTENTS}

1. INTRODUCTION 1

2. INSTRUMENT .........................................................

3. REQUIREMENTS AND DATA....................................

4. PERFormance of MEASUREMENTS ....................4

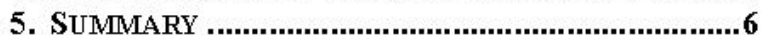

REFERENCES ...........................................................

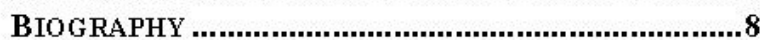

\footnotetext{
1

${ }^{1}$ U.S. Government work not protected by U.S. copyright.

${ }^{2}$ EEEAC paper \#1584, Version 3, Updated October 29, 2007
}

\section{INTRODUCTION}

Space borne observations by a high performance polar orbiting lidar was initiated in 2003 by the launch of the Geoscience Laser Altimeter System (GLAS) shown in Figure 1. Measurements have now provided fundamentally new results. We concern ourselves here with atmospheric applications on the global distribution of clouds and aerosol in this paper [1]. More generally GLAS was developed as a comprehensive earth sensing lidar for both surface and atmospheric applications [2]. The surface measurements have shown some significant results [3].

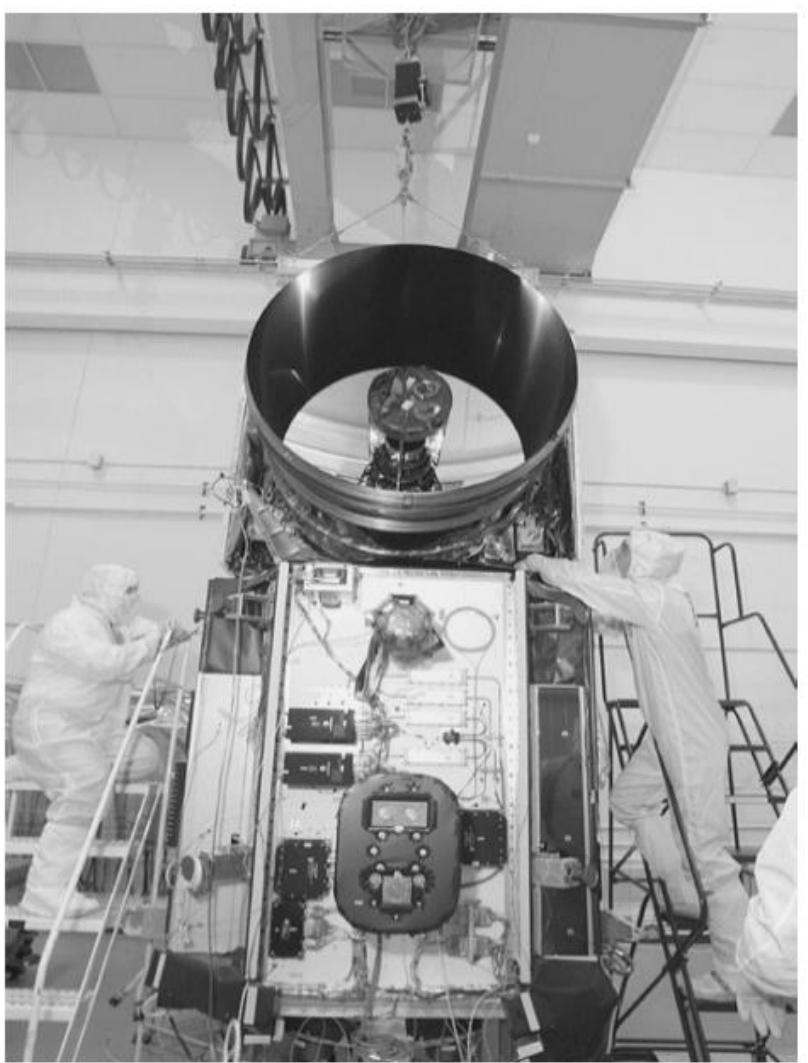

Figure 1 GLAS in strument on satellite

The primary advance from the active optical sensing of the atmosphere is an unambiguously accurate, and highly resolved, measurement of the distribution for atmospheric 
scattering layers. In addition the lidar data provides an extremely sensitive detection of the thinnest aerosol and cloud layers and their optical thickness. For clouds, the initial analyzed results for GLAS show the total global cloud cover is $76 \%$, over $15 \%$ higher than accepted amounts, and cloud overlap, defined as the detection of a second cloud layer before full optical attenuation, is found to be present in $40 \%$ of cloudy areas globally, a fundamentally new observation. If an optically opaque atmosphere is defined as a lack of a laser signal from the surface, then GLAS finds a surprising $49 \%$ of the global atmosphere to be optically opaque. The global pattern of retrieved cloud altitude is significantly different than results from passive sensors [4]. Cloud distribution and coverage in Polar regions is an especially important application [5]. Passive retrievals do not fare well underlain with bright low temperature surfaces. Coverage is also best in polar latitudes with representative sampling on a daily basis as indicated in Figure 2.

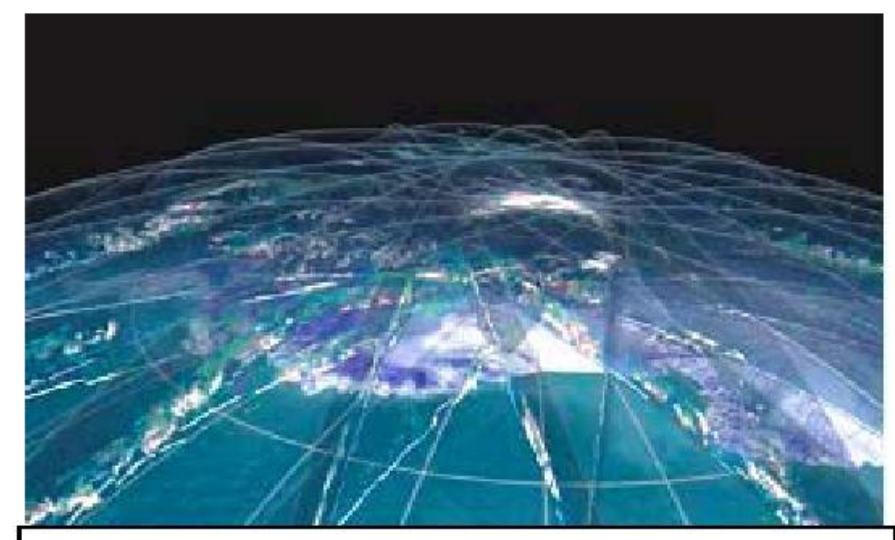

Figure 2 Depiction of one day of GLAS measurements over Antarctica. The measurements give a very accurate detection and height profile of all significant clouds and aerosol layers in the atmosphere, but the coverage is limited to nadir only profiling.

For atmospheric aerosol, GLAS observations represent the first global measurements of the true height distribution. In addition lidar gives a much more sensitive detection of aerosol layers than passive sensors and is not biased by land background. Data are analyzed for aerosol optical depth and extinction cross section with special retrieval methods. Values obtained have an advantage for accurate measurements of low optical depth. Some results for GLAS aerosol measurements have already been reported. From interpretation of the aerosol height distribution a unique global data product of PBL height is produced. The PBL (planetary boundary layer) height data have been applied as a new validation for the ECMWF and other global circulation models [6]. Data have also been used to determine the faction of the global atmosphere that is "clear" [7]. Defining clear as aerosol and cloud optical depths of less than 0.01 , this initial analysis of GLAS data shows $20 \%$ of the global atmosphere as clear. Hart et al. [8] show how data define the height distribution between aerosol and cloud in the PBL.
The initial full operation of GLAS began in fall of 2003 and the initial data products, as reported in the papers mentioned above, were released in 2004 . Since that time there has been an ongoing process of analyzing results and improvement in the quality and comprehensiveness of measurements and products, such as occurs for all satellite missions. Studies include the statistical analysis of results, quality-checking surveys, inter-comparison of algorithms and comparison to ground and airborne measurements. Before launch there were well-defined science requirements that the measurements and algorithms were to accomplish. A question is how well were these goals realized. This paper describes the effectiveness, results and limitations of the lidar channel design and data product algorithms to the current time.

Instrument problems, especially laser reliability, have affected the quality and length of all GLAS observations. The GLAS data are currently limited to less than two years, but high quality data to three months. Nerveless the global measurements for even this time period represent a significant new result for aerosol, radiation and global change research. Unique characteristics of the GLAS instrument leave many of the measurements and results to be unique for the foreseeable future, and their quality and accuracy a mater of importance.

\section{INSTRUMENT}

GLAS is a nadir viewing laser radar system. Diode pumped $\mathrm{Nd}$ :YAG lasers transmit at both the fundamental and doubled wavelengths. Three lasers were to be used singly. The receiver is dual wavelength and dual purpose. The $1064 \mathrm{~nm}$ channel applies analog signal acquisition for surface ranging and dense cloud tops. The $532 \mathrm{~nm}$ channel uses high efficiency GAPD solid-state detectors for photon counting signal acquisition and is the primary channel for aerosol signal acquisition. Important aspects of the $532 \mathrm{~nm}$ atmospheric receiver channel are the small FOV and a very narrow band filter to minimize the solar background noise signal and enable daytime observations.

Table 1. Nominal GLAS instrument parameters
\begin{tabular}{|l|l|l|}
\hline PARAMETERS: & $532 \mathrm{~nm}$ & $1064 \mathrm{~nm}$ \\
\hline Laser Pulse Energy & $36 \mathrm{~mJ}$ & $74 \mathrm{~mJ}$ \\
\hline Laser PRF & $40 \mathrm{~Hz}$ & $40 \mathrm{~Hz}$ \\
Telescope Diameter & $0.9 \mathrm{~m}$ & $0.9 \mathrm{~m}$ \\
\hline Receiver FOV & $0.19 \mathrm{mrad}$ & $0.5 \mathrm{mrad}$ \\
\hline Optical Bandwidth & $25 \mathrm{pm}$ & $1.4 \mathrm{~nm}$ \\
\hline Detector Quantum Efficiency / Type & $\begin{array}{l}0.7 / \mathrm{GAPD} \text { photon } \\
\text { count }\end{array}$ & $0.3 / \mathrm{APD}$ analog \\
\hline Range resolution & $75 \mathrm{~m}$ & $0.075 \mathrm{~m} \mathrm{\&} 75 \mathrm{~m}$ \\
\hline
\end{tabular}

The wavelengths, pulse rate and other parameters are listed in Table 1 . Since dense cloud signals could saturate the photon counting, the full atmospheric signal is also acquired with analog detection at $1064 \mathrm{~nm}$ used for surface altimetry. Special design features of GLAS to allow the instrument to accomplish surface altimetry are an advantage for the atmosphere measurements. These include a precise integrated, 


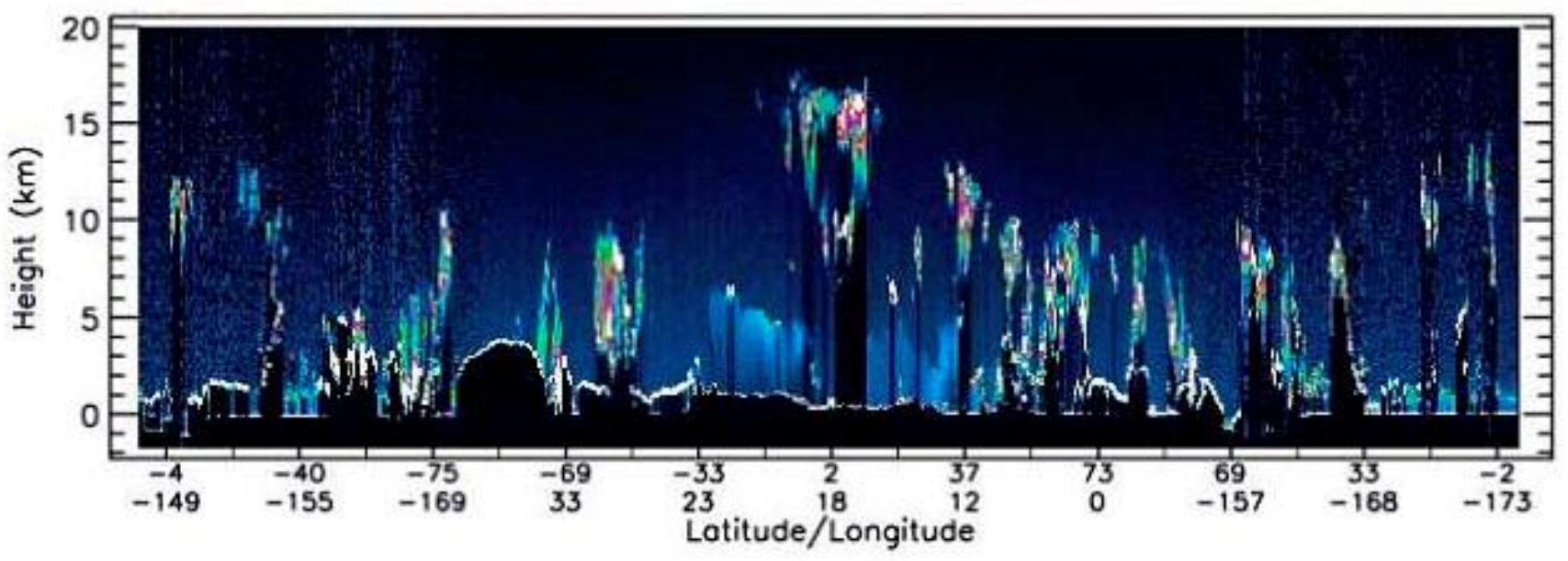

Figure 3 GLAS $532 \mathrm{~nm}$ data for global or bit.

Table 2. GLAS Atmospheric Data Products

\begin{tabular}{|c|c|}
\hline $\begin{array}{l}\text { - GLA02 } \\
\text { - GLA0T } \\
\text { - GLA09: } \\
\text { - GLA09 }\end{array}$ & $\begin{array}{l}532 \text { ard } 1064 \text { yor ralized lidar signal } \\
\text { Ca librated, atte ruated backsatter cros section profiles for } 532 \text { and } 1064 \text { at } \\
40 \mathrm{~Hz} \text { and } 5 \mathrm{~Hz} \\
\text { Planetary Boundary Layer ( } 5 \mathrm{~Hz} \text { and } 4 \mathrm{sec} \text { ) height ard e levated aerosol layer } \\
\text { top ard bo thorn he ight } \\
\text { Cloud layer top and bottorm heig ht at } 40 \mathrm{~Hz}, 5 \mathrm{~Hz}, 1 \mathrm{~Hz} \text { and } 4 \text { seconds }\end{array}$ \\
\hline $\begin{array}{l}\text {-GLA } 10 \\
\text { - GLA11 }\end{array}$ & $\begin{array}{l}532 \text { attenuation corrected backscatter and extinction profiles } \\
\text { Thin cloud and aerosol layer optical depth. }\end{array}$ \\
\hline
\end{tabular}

and $15 \mathrm{~cm}$ resolved measurement of the sufface pulse waveform, the ability to point to validation targets with $50 \mathrm{~m}$ accuracy and a $94^{\circ}$ orbit inclination for good cover age of polar regions.

\section{REQUIREMENTS AND DATA}

The first on orbit full operation of the GLAS instrument comencede in 28 September 2003. An ex ample of the 532 nm data is shown in Figure 3 for a single, global orbit track on October 6. Data are color scale coded in the image as the normalized attenuated backscatter (NAB) return corrected for solar background off sets. The track starts in the central Pacific, crosses Antarctica, proceeds over Africa and Europe and then covers nor thern Greerland and Alaska. These data, and other s from thousands of such orbits, illustr ate the ability of space lidar to accurately and dratnatically measure the height distribution of global cloud and aerosol to an unprecedented degree. The data show boundary layer aerosol and PBL height over the clean Pacific, elevated dust layers over Africa, the distribution of high thin cloud (and associated tropopause height) and multi-layer clouds. Many specific, unique atmospheric phenomena have been profiled for the fir st time on a global basis.
The measurement recuirement for GLAS atmospheric observations were stated most basically as measuring the vertical NAB distribution for all sigrificant cloud and aerosol scattering defined as values down to $10^{-7} 1 / \mathrm{m}$-s for $20 \mathrm{~km}$ horizontal resolution. The $1064 \mathrm{~nm}$ channel was not intended to be as sensitive but has preformed better than expected. An example of the 532 and $1064 \mathrm{~nm}$ data for the same track over and north of Australia is shown in Figure 4. Both channel show smoke related aerosol emanating from convective clouds over Australia but structure is much more defined and extensive in the $532 \mathrm{~nm}$ data. At the right of the images, both chamels show tropical boundary layer aer osol with cross sections greater than $10^{-6} 1 / \mathrm{m}$-sr.

As an EOS project recuirement, the GLAS science team is responsible for developing algorithms for instrument level correction of data, data calibration and higher-level data products for general research applications, and in adclition data product valication. A list of the GLAS atmospheric data products is given in Table 2. The GLA02 and GLA07 products are the lidar signal with instrument corrections and calibration. Products 08 through 11 are higher-level results derived through retrievals dependent on the 

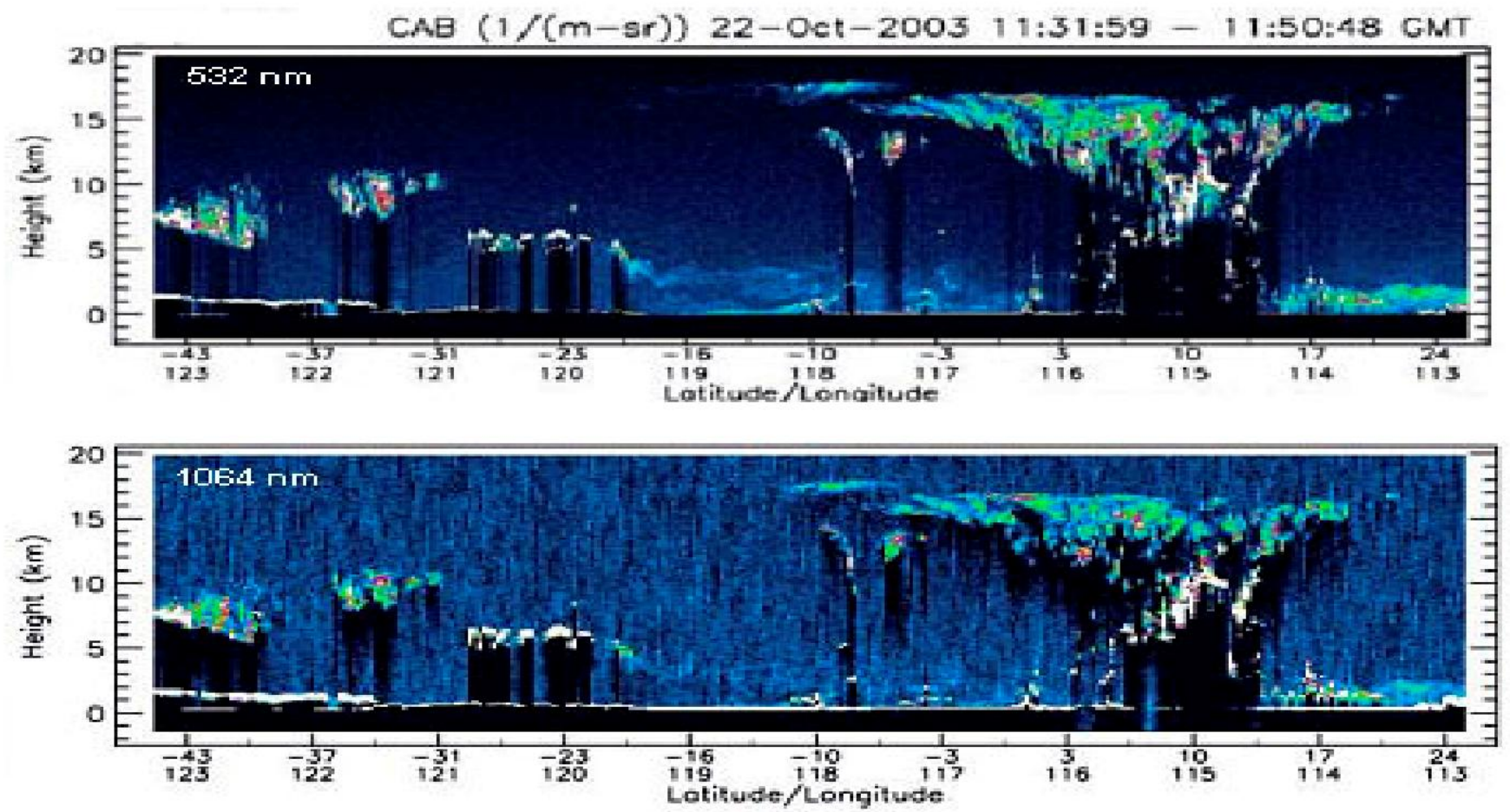

Figure 4 GLAS 532 and 1064 nm data over Australia and Pacific warm pool region

particular algorithms developed by the GLAS atmospheric group. An illustration of GLA07, GLA09 GLA10 and GLA11 are shown in Figure 5 for data of cloud and aerosol layers from a portion of a GLAS orbit track over Europe on October 19, 2003. In Figure 5 both cloud and aerosol products are shown together, however the processing algorithms employ a sophisticated segregation of aerosol and cloud layers and are so flagged in the data products.

The GLAS measurements provide the capability to resolve atmosphere scattering layers from resolutions below $100 \mathrm{~m}$ to globally girded data results. One of the measurements is the accurate detection and definition of heights for cloud and aerosol layers. From the corrected signals a sophisticated thresholding and filtering routine is used to determine the upper and lower boundaries of scattering layers, and further multi component analysis is applied to discriminate between cloud and aerosol layers, illustrated in Figure 6, up to the limit of signal attenuation. Independent algorithms are applied between the two wavelength channels. As expected, for layers of low optical thickness the $1064 \mathrm{~nm}$ results are less accurate.

The second major class of data products for atmospheric observations are the optical depth and height distribution of extinction cross section for aerosol and thin cloud layers. These parameters are derived from algorithms employing several approaches including in appropriate cases a direct retrieval based on attenuation of the molecular scattering signal or the surface return signals. An important part of the optical depth retrieval is the correction for multiple scattering [1]. The initial data algorithms for optical thickness were only applied at the $532 \mathrm{~nm}$ wavelength, but currently the additional use of the $1064 \mathrm{~nm}$ channel is under development. Algorithms have gone through successive improvements since the operational inception, and overall currently are verified to perform close to expected accuracies. Also recent releases have more thorough and extensive quality checking and ground truth intercomparison.

\section{Performance of Measurements}

Both atmospheric receiver channels are found to meet their design goals within the limits of known instrument problems at the time of launch. The Geiger Mode Avalanche Photodiode modules used for the $532 \mathrm{~nm}$ signals have a measured detection probability of better than $65 \%$. The operational experiences with the GAPD modules are that some signal artifacts and non-linearity require correction in data processing. As with all photon counting detectors, a pulse-pile-up calibration is an important aspect of the measurement. Additional signal corrections were found to be necessary relating to correction of a saturation signal-run-on effect and also for daytime data, a small range dependent variation in the responsivity thought to be related to diode heating effects. It was possible to correct for these signal errors in data processing and achieve the requirement to accurately profile aerosol and cloud cross section down to $10^{-7} 1 / \mathrm{m}$-sr with pulse averaging. The analysis procedure employs a precise cross section calibration against midstratosphere molecular scattering. The $1064 \mathrm{~nm}$ channel 


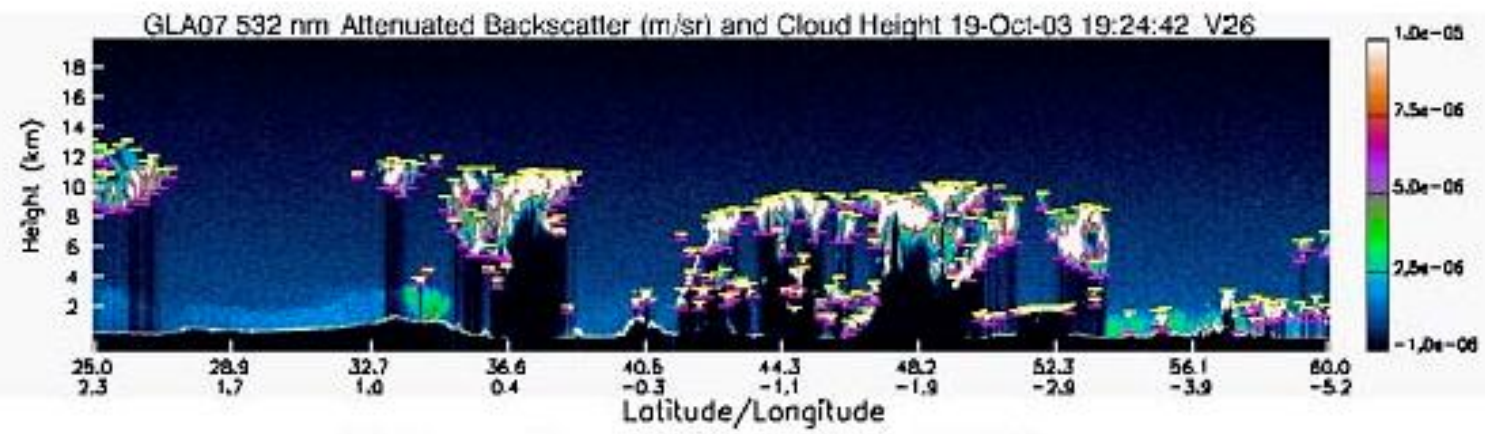

GLAS Loyer and Ground Heights for 10-19-2003 $532 \mathrm{~nm}$
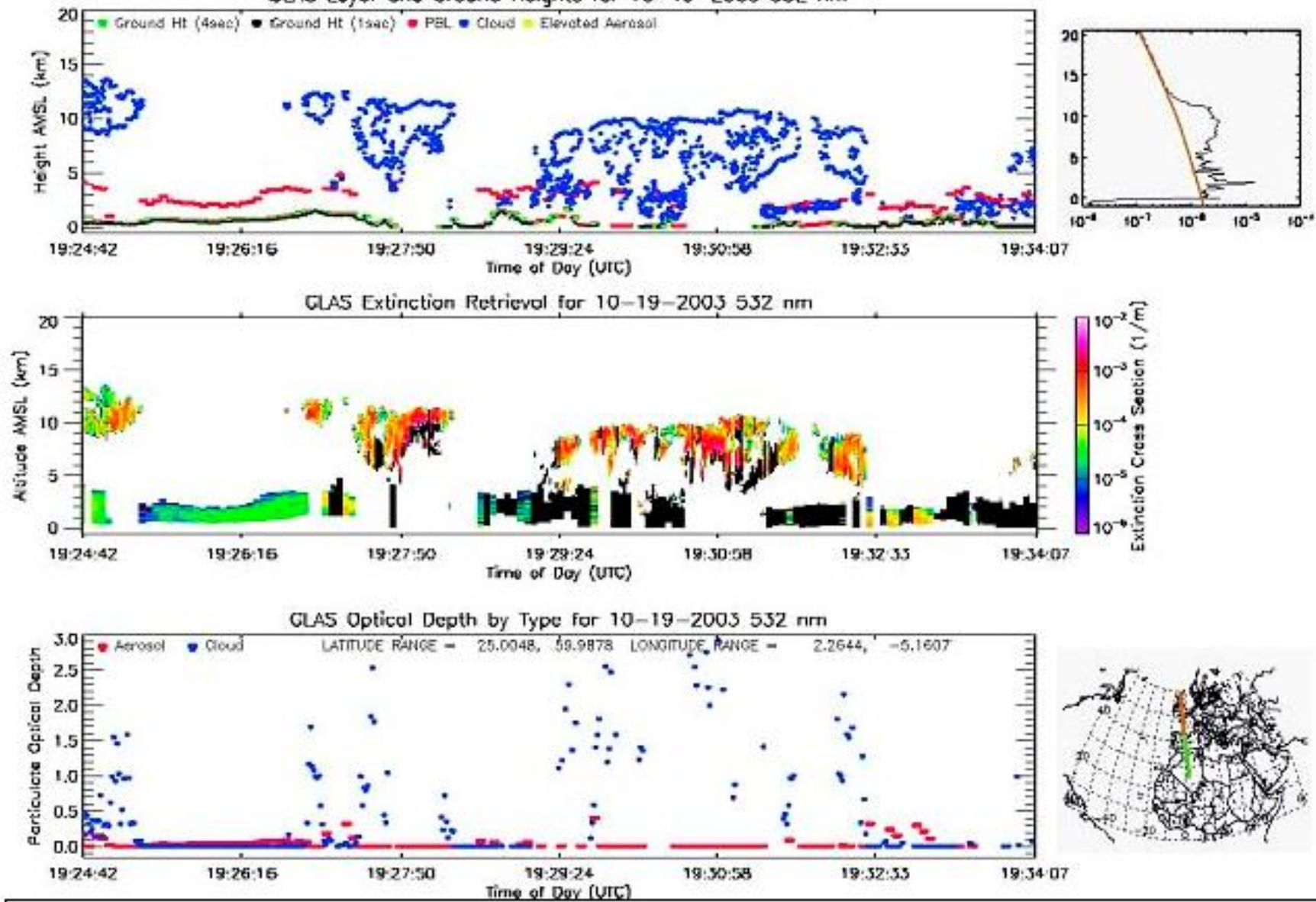

Figure 5. An example of the GLAS atmospheric data products. In the top frame is shown the GLA07 attenuated backscatter cross section at $532 \mathrm{~nm}$. In the second frame are the GLA08, 9 cloud and aer osol layer boundary heights. The small $\mathrm{graph}$ to the right is the average observed cross section for the line. The other frames are the GLA10, 11 extinction cross section and optical depths. The bottom right graph shows the location of the data track. These data survey images are available for all of the $532 \mathrm{rm}$ data through our web-based interface.

detection using a high-speed analog APD for surface applications limits atmospheric measurements, as the atmospheric detection is impacted by detector noise. Sensitivity is observed to be approximately an order of an order of magnitude less than at $532 \mathrm{~nm}$.

Overall results have verified the advantage of high performance photon counting signal application for a space borne lidar. Field experiments for validation of GLAS calibration and data products are part of science team activities [9]. The principle experimental validation approach for the atmospheric measurements has been under flights by the NASA ER-2 aircraft and use of surface networks by taking advantage of the $50 \mathrm{~m}$ off nadir pointing accuracy of the instrument. Hlavka et al. [9] describes comparison to airborne lidar and radiometers. The principal justification that clouds and aerosol layers with cross sections down to $10^{-7} 1 / \mathrm{m}$-sr with pulse averaging over $20 \mathrm{~km}$ were detectable in the $532 \mathrm{~nm}$ data, when the laser pulse quality was good, comes from the airborne 
intercomparison. Also a statistical analysis of data indicates layers with cross section below $10^{-7} 1 / \mathrm{m}$-sr are detected during 2003-2004 operations when the $532 \mathrm{~nm}$ laser pulse energy was sufficient strong.

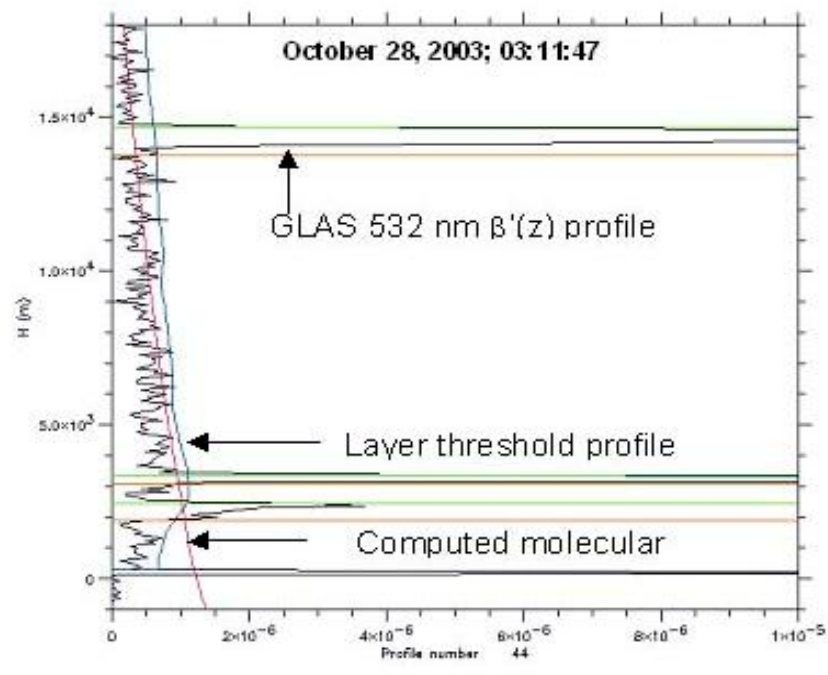

Figure 6 An example of the GLAS $532 \mathrm{~nm}$ signal and layer detection procedure. The data are for a 1 second average. The backscatter calibration is obtained by comparing signals above $25 \mathrm{~km}$ averaged for several minutes to the molecular profile computed from temperature profile data. For layer detection, a variable section of data of up to minute is analyzed to construct a layer threshold profile based on the molecular signal and average attenuation. Deviations beyond the threshold of more than a single point significance trigger a layer boundary detection, as indicated by the red line.

The most difficult of the lidar data products in terms of measurement and algorithms complexity is the optical thickness of layers and the related extinction cross section. Either a forward solution of the lidar equation is used with a model derived lidar ratio or the direct attenuation of the molecular signal under the layer is analyzed [9][10]. The requirements for these approaches are summarized in Table 3. For cirrus it has been found possible to apply the latter solution in approximately one half of global cases. For the direct molecular based solution, the lidar scattering ratio is derived, not assumed. An important validation of the layer optical depth results is the fact that the retrieved scattering ratio's agree well on average with modeled scattering ratio's applied for the forward solution.

The overall efficacy of the cirrus and other thin cloud optical depth retrievals has been studied by looking at the spatial and frequency distribution of results. A frequency plot of the cloud layer optical thickness in the GLAS retrieval s for clouds above $6 \mathrm{~km}$ globally for October 2003 is shown in Figure 7. As is seen for the $532 \mathrm{~nm}$ data for night time, the distribution peaks at approximately 0.02 indicating that layers below 0.01 are retrieved. The day time data is less sensitive as a result of solar background noise, and does not meet original requirements. The failure in this regard is largely due to signal degradation due to known instrument problems at launch that resulted in approximately a factor of four less sensitivity than intended. The curves for the $1064 \mathrm{~nm}$ channel represent the cloud detection frequency in the channel for layers of the retrieved $532 \mathrm{~nm}$ optical depths. As expected the cloud detection effectiveness for low optical thickness layers is significantly less, although there is less day-night variation.

\section{SUMMARY}

There were multiple intended science applications of the GLAS data and significant results have been realized. The atmospheric applications were primarily to be realized by a receiver design employing low noise, high efficiency photon counting detectors in a channel at $532 \mathrm{~nm}$. The design has proved to perform very well, given the on orbit failure of the laser reliability and other instrument problems know before launch. Analysis of algorithm performance shows mostly good results. One measurement application is the accurate height distribution and coverage of global cloud cover with one goal of defining the limitation and inaccuracies of passive retrievals. Initial comparisons to NOAA $14 \& 15$ satellite and other passive cloud retrievals show basic similarity in overall cloud coverage, but important differences in height distribution. Because of the especially poor performance of passive cloud retrievals in polar regions, and partly because of high orbit track densities, the GLAS measurements are by far the most accurate measurement of Arctic and Antarctica cloud cover from space to date [5]. Global aerosol height profiling is a fundamentally new measurement from space with multiple applications $[6][7][8]$. A most important aerosol application is providing input to global aerosol generation and transport models. Another is improved measurement of aerosol optical depth. Oceanic surface energy flux derivation from PBL and LCL height measurements is another application of GLAS data that is being pursued.

Table 3 GLAS Basic Measurem ent Requirements for Clouds and Aerosol Optical Thickness
Thin Cloud OD Retrieval
Molecular $\mathrm{x}$-section to $10^{-8} 1 / \mathrm{m}$-sr with $2 \%$ accuracy at $5000 \mathrm{~km}$ resolution
Thin Cloud OD to 0.01 with $30 \%$ accuracy at $25 \mathrm{~km}$ resolution
Aeros ol OD Retrieval
Aerosol OD to 0.01 with $20 \%$ accuracy at $100 \mathrm{~km}$ 


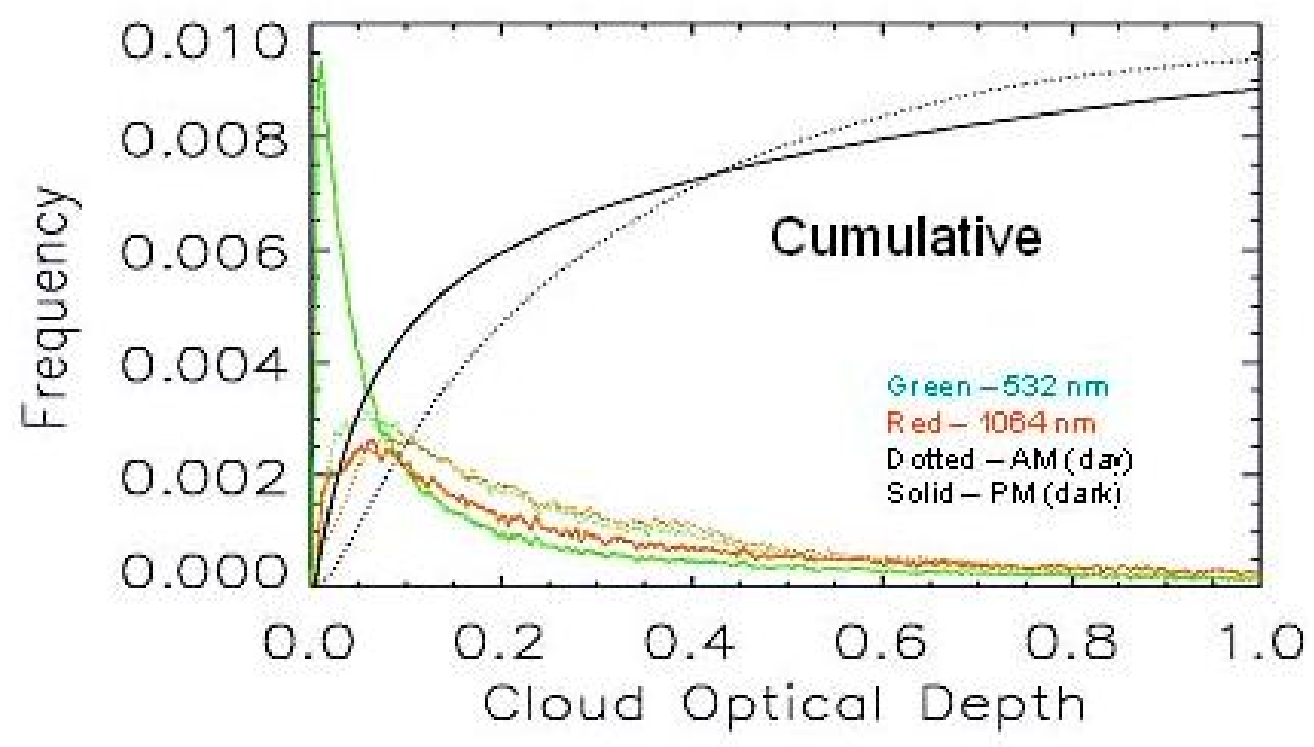

Figure 7 Cloud optic al thickness relative frequenc $y$ of occurrence. The full analys is of clouds above $6 \mathrm{~km}$ is shown for global retrievals of October, 2003. Results indicate the sensitivity for layer detection and optical thickness retrieval extend to below 0.01 for righttime data. The result thus serves as a baseline for other global cloud and aerosol measuremerts. The difference in low optical thickness sensitivity between the day and rizht results is larger than intended due to on orbit instnument problems. The $1064 \mathrm{num}$ curves represent the cloud detection frequency acquired inde pendently from $1064 \mathrm{~nm}$ data for the given $532 \mathrm{~nm}$ COD.

The GLAS instrument was designed with three lasers to obtain a three to five year mission life. Life testing indicated that each laser should last for two years. During the initial on orb it test operation with the first GLAS laser there was a premature faibure of a pump diode module and on the second and third laser early degradation of power due to a suspected contamination is sue. After the two months of fill operation in the fall of 2003 the plan for GLAS has been to operate for a one-month periods out of every three to six morths in order to extend the time series of measurement, particularly for the ice sheet. Only data in fall 2003 and February 2004 have good quality $532 \mathrm{~nm}$ atmospheric data. The laser reliability faibure limits the use of the data for climate applications requiring a time series of measurements. Overall the mission has clearly demonstrated the important application for space bome lidar and created a unique data set form thousands of orb its with mary research applications. In addition the atmos pheric group maintains a web portal, listed below, with convenient access to quick look images of all data and other infomation such as documents describing the data algorithms. As an EOS mission, GLAS data are freely available through the WASA Distributed Active A rchive Centers (DAAC) system. Both data sets and data input and visualization tools are available.

Other satellite lidar rrissions are to follow. The initial GLAS mission is to be succeeded by a second science instrumert, possibly launched as early as 2012 . As currently conceived at Goddard S pace Flizht Certer, it would primarily be a less ambitions surface altimeter and only inchede the capabilities of the $1064 \mathrm{~nm}$ channel of the current instrumert, inchuding the cloud measurements. As is well known, another, less techuically complex and inde pendently de veloped, NAS a cloud and aerosol lidar is currently in a $98^{\circ}$ ortit and is operating with success ful laser reliability. Additionally ESA has two satellite lidars in development, including a highly sophistic ated Doppler lidar for wind measurements. The management directive for the initial GLAS satellite lidar was a rapid developmert and hizh-risk instrument teclmology demonstration. As such, even with its laser reliability faihure, it is the first successful earth observation lidar in space with mary more instrumerts to follow.

\section{REFERENCES}

1. J. D. S pirhime, S. P. Palm, W. D. Hart, D. L Hlavka and E J. Welton, "Clond and aerosol measurements from GLAS: overview and initial results", Geophs. Res. Lett., 32, L22S03, doi:10.1029/2005GL023507, 2005.

2. Zwally H. J., B. Sclutx, W. Adbalati, J. Abshire, C. Bertley, A. Brenner, J. Buftom, J. Dezio, D. Hancock, D. Harding, T. Hering, B. Minster, K. 
Quinn, S. Palm, J. Spinhirne, R. Thomas, J "Ice, Cloud and land Elevation Satellite's laser measurements of polar ice, atmosphere, ocean and land," Geodyn., 34, 405-445, 2002.

3. Fricker, H. A., T. Scambos, R Bindschadler, L. Padman, "An Active Subglacial Water System in West Antarctica Mapped from Space", Science, 315. no. 5818 , pp. $1544-1548,2007$.

4. Wylie, D., E. Eloranta, J. D. Spinhirne and S. P. Palm, A comparison of cloud cover statistics from the GLAS lidar with HIRS J. of Climate, (in press), 2007

5. Spinhirne, J. D., S. P. Palm, and W. D. Hart (2005), Antaretica cloud cover for October 2003 from GLAS satellite lidar profiling, Geophys. Res. Lett., 32, L22S05, doi:10.1029/2005GL023782.

6. S. P. Palm, A. Benedetti, J.D Spinhime, W. Hart and D. Hlavka, "Validation of ECMWF global forecast model parameters using GLAS atmospheric channel measurements," Geophs. Res. Lett., 32, L22S09, doi:10.1029/2005GL023535, 2005.

7. M. Bréon, D. M. O'Brien, and J. D. Spinhirne, "Scattering layer statistics from space borne GLAS observations", 2005 F. Geophys. Res. Lett., 32, L22802, doi:10.1029/2005GL023825.

8. W. D. Hart, J. D. Spinhirne, S. P. Palm, and D. Hlavka, "Height distribution between cloud and aerosol layers in the Indian Ocean region from the GLAS spaceborne lidar", Geophs. Res. Lett., 32, L22S06, doi:10.1029/2005GL023671, 2005.

9. D. L. Hlavka, S. P. Palm, W. D. Hart, J. D. Spinhirne and E. J. Welton, "Aerosol and cloud optical depth from GLAS: Results and verification for an October 2003 California fire smoke case," Geophs. Res. Lett., 32, L22S07, doi:10.1029/2005GL023413, 2005 .

10. D. L. Havka W. D. Hart, S. P. Palm, and J. D. Spinhirne, "column optical depth retrieval using surface reflectivity from glas," Extended abstract of 12th Conference on Atmospheric Radiation, AMS, Madison, 2006 Mahesh, M. A. Grey, S. P. Palm, W. D. Hart and J. D. Spinhirne,"Passive and active detection of clouds: Comparisons between MODIS and GLAS observations," J. Geophys. Res., 108, L04108-L04108, 2004.

11. Palm, S. P., J. D. Spinhime, W. D. Hart and D. L. Hlavka, "Algorithm Theoretical Basis Document for the Geoscience Laser Altimeter System, Atmospheric Data Products" NASA intemal document, at http://www.csr.utexas.edu/glas/, 2002.

Internet web address: http://glo.gsfe.nasa.gov/ Internet web address: http://nsidc.org/daac/icesat/

\section{BIOGRAPHY}

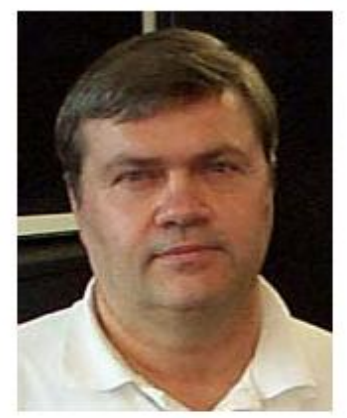

James D. Spinhirne is currently a scientist at the Goddard Laboratory for Atmospheres, NASA-Goddard Space Flight Center, in Greenbelt, MD. His research work includes advances in remote sensing, atmospheric radiation and climate, instrument development and observations with a specialty in lidar measurements. $\mathrm{He}$ is a developer and science team member for the Geoscience Laser Altimeter System spacecraft instrument now in orbit. $\mathrm{He}$ is the principal investigator of multiple aireraft instruments and experiments and of the Infrared Spectral Imaging Radiometer (ISIR) Space Shuttle experiment successfully flown on STS-85. He developed Micro Pulse (MP) Lidar technology and initiated the global MP Lidar observation network. Dr. Spinhime is a Fellow of the Optical Society of America. He earned his Ph.D. in atmospheric sciences in 1976 , and an M.S. in electrical engineering in 1974, at the University of Arizona. He also holds a 1970 B.S. in physics from the University of Illinois. 